\title{
Non-acquired combined pituitary hormone deficiency-sensorineural hearing loss-spine abnormalities syndrome
}

INSERM

\section{Source}

INSERM. (1999). Orphanet: an online rare disease and orphan drug data base. Nonacquired combined pituitary hormone deficiency-sensorineural hearing loss-spine abnormalities syndrome. ORPHA:231720

Non-acquired combined pituitary hormone deficiency-sensorineural hearing loss-spine abnormalities syndrome is a rare, genetic, non-acquired, combined pituitary hormone deficiency disorder characterized by panhypopituitarism (with or without ACTH deficiency) associated with spine abnormalities, including frequent rigid cervical spine and short neck with limited rotation, and variable degrees of sensorineural hearing loss. The anterior pituitary gland is usually abnormal (typically hypoplastic) and rarely a mild developmental delay or intellectual disability may be associated. 